\title{
Theories of Practice and Sustainable Consumption
}

Link to publication record in Manchester Research Explorer

\section{Citation for published version (APA):}

Welch, D., Warde, A., Reisch, L. (Ed.), \& Thøgersen, J. (Ed.) (2015). Theories of Practice and Sustainable Consumption. In Handbook of Research on Sustainable Consumption (pp. 84-100). Edward Elgar Publishing Ltd.

\section{Published in:}

Handbook of Research on Sustainable Consumption

\section{Citing this paper}

Please note that where the full-text provided on Manchester Research Explorer is the Author Accepted Manuscript or Proof version this may differ from the final Published version. If citing, it is advised that you check and use the publisher's definitive version.

\section{General rights}

Copyright and moral rights for the publications made accessible in the Research Explorer are retained by the authors and/or other copyright owners and it is a condition of accessing publications that users recognise and abide by the legal requirements associated with these rights.

\section{Takedown policy}

If you believe that this document breaches copyright please refer to the University of Manchester's Takedown Procedures [http://man.ac.uk/04Y6Bo] or contact uml.scholarlycommunications@manchester.ac.uk providing relevant details, so we can investigate your claim.

\section{OPEN ACCESS}




\title{
Theories of practice and sustainable consumption
}

\author{
Welch, D. and Warde, A. (2015) "Theories of Practice and Sustainable Consumption", in \\ Reisch, L. and Thøgersen, J. (eds.) Handbook of Research on Sustainable Consumption, \\ Cheltenham, UK: Edward Elgar Publishing, pp.84-100
}

Daniel Welch and Alan Warde, University of Manchester

\section{Daniel.welch@manchester.ac.uk}

The year 2001 saw the publication of a book entitled The Practice Turn in Contemporary Theory (Schatzki et al. 2001). More a declaration of intent than a monument to a newly established orthodoxy, it marks a point of theoretical confluence which has had significant impact on the study of sustainable consumption. Theories of practice - in the plural, for there is no single accepted version of such a theory - are applicable in principle to any domain of activity, and have been adopted for use within many social scientific disciplines, but they seem to have produced particularly promising applications in the understanding of sustainable consumption. Theories of practice make several moves in the explanation of personal conduct and social organization which are unorthodox. For example when giving an account of human activity the roles of conscious intention, of individual autonomy and of decision making are played down, and explanation focuses on the organization of practices rather than on individuals.

Such recalibrations of perspective throw a different light on activities such as consumption and, a fortiori, on sustainable consumption. Protecting Planet Earth from the consequences of human-induced climate change and environmental degradation will be a formidable, collective, political endeavour which entails a radical transformation in the patterns, forms and levels of consumption in wealthier societies. Research conducted under the auspices of theories of practice has picked up on the near impossibility of current responses successfully resolving the problem. This chapter is therefore designed against the background of a highly intractable set of political difficulties upon which a new theoretical perspective offers fresh insight about the nature of the problem and its solution.

In this chapter we present a brief history of the construction of basic elements of the theories of practice as formulated in the later twentieth century. There are many disputes within the camp of practice theorists and the general movement is very much a project still in the making. Exposition of internal differences in approach is therefore essential, even at the expense of exposition being sometimes rather detailed. We present the development of practice theoretical approaches to sustainable consumption by way of a (somewhat stylized) contrast between two research programmes: one emerging from ecological modernization theory, the other more entrenched in or heavily dependent upon current 'strong' revisions of theories of practice. We detect some degree of convergence between the two at the beginning of the second decade of the twenty-first century. Nevertheless the contrast serves to reveal points of tension within practice-theoretical-inspired research strategies and to identify contrasting proposals for political intervention in the name of sustainability. Consequently we reveal some of the internal problems of theories of practice, some of which they have been (sometimes tortuously) resolved. We conclude by identifying three analytic problems whose clarification and resolution would enhance the power of practice theories: the first concerns the relationship between production and consumption; the second concerns the relationship between collective agency and quotidian routine; and the 
third concerns the relationship between the minutiae of everyday performances of practices and the macro-institutional context.

\subsection{THE DEVELOPMENT OF THEORIES OF PRACTICE}

Theories of practice are currently widely employed across the disciplines of the humanities and social sciences and have become increasingly prominent in discussions of sustainable consumption. We refer to theories in the plural because there are several different, though of course related, versions. Concepts of practice and praxis have a long history in the social sciences (see Nicolini 2012). However the forms in which they are currently manifested derive from attempts in the 1970s to resolve some fundamental puzzles in social theory, ones of particular interest to sociologists and anthropologists (Ortner 1984; Rouse 2006). Probably the most important of these was the issue of the relationship between structure and agency, but controversy over the relative merits of holism and methodological individualism was also significant.

Recently Nicolini (2012) has surveyed in magisterial fashion the full and wide range of practice theories now in circulation. He distinguishes between: the praxeological theories of Giddens (1984) and Bourdieu (1977); practice as tradition and community (Wenger 1998; MacIntyre 1981); practice as activity (Vygotsky and cultural and historical activity theory); practice as accomplishment, in the manner of ethnomethodology; practice as the locus of the social (as in Schatzki's 1996, 2002 reworking of Heidegger and Wittgenstein); and practice as discourse, which he elaborates via conversation analysis and a review of Foucault. It is difficult to specify what these theories have in common. Nicolini (2012) concurs with Schatzki (2001) that there is no unified practice approach. Nevertheless he notes 'a number of family resemblances' among theories from which he isolates some suggestions for how to undertake empirical studies (Schatzki 2001, p. 11). Reckwitz (2002) helpfully observes that while all cultural theories oppose both the utilitarian or rationalchoice models of social action and order, and the classical sociological norm-orientated model of social action and order (that is, Durkheim and Parsons), what unites the heterogeneity of practice theories is the contention that social order and action is a feature of, and established through, the field of human practices. Practice theories' central claim is to move beyond problematic dualisms like structure and agency, methodological individualism and holism, determinism and voluntarism, and subject and object. Moreover, as Schatzki (2001, p. 14) suggests, 'these accounts all undermine the traditional individual-nonindividual divide by availing themselves of features of both sides'. Social practices, then, rather than individuals (and their attitudes and preferences), norms, cultural codes, discourses, macro-level trends or social structures become the central unit of analysis; and in policy-oriented accounts of sustainable consumption, they become the central unit of intervention (Shove 2010; Shove and Walker 2010; Spurling et al. 2013).

Whilst there is considerable variation in the definition of what constitutes a social practice, ${ }^{1}$ a minimal definition might be an organized, and recognizable, socially shared bundle of activities that involves the integration of a complex array of components: material, embodied, ideational and affective. Practices are sets of 'doings and sayings'; they involve both 'practical activity and its representations' (Warde 2005, p. 134).

A useful analytical distinction can be made between practices as performances and practices as entities (Schatzki 1996; Shove et al. 2012; Warde 2005). Practices as entities have a history and a trajectory, or path of development, but at the same time only exist through their performance. Performance and entity are therefore recursively related rather as agency and structure in Giddens's theory of structuration.

Theories of practice began to be applied explicitly to the analysis of consumption at the beginning of the twenty-first century. Warde's (2005) paper, 'Consumption and theories of practice', is widely regarded as the first programmatic application of practice theory to 
the field of consumption (e.g. Halkier et al. 2011; Røpke 2009). Perhaps the central contribution of the paper is to reconceptualize consumption as 'not itself a practice but ... rather, a moment in almost every practice' (Warde 2005, p. 137). Thus for Warde, whilst there are practices in which people may understand their behaviour as 'consuming', such as shopping, these are by far the exception amongst practices in which consumption is a moment. The figure of 'the consumer' is decentred from accounts of consumption as 'wants are fulfilled only in practice, their satisfaction attributable to effective practical performances' (Warde 2005, p. 142):

"The analytic focus shifts from the insatiable wants of the human animal to the instituted conventions of collective culture, from personal expression to social competence, from mildly constrained choice to disciplined participation. From this angle the concept of 'the consumer' ... evaporates. Instead the key focal points become the organization of the practice and the moments of consumption enjoined." (Warde 2005 p. 146)

Warde defines the generic components of practice as: understandings (know-how and practical interpretation), procedures (rules, principles, instructions) and engagements (affective and normative orientations). The identification of the components of practice, their coordination, histories and dynamics, thus becomes a core task for the analysis of practices in the field of sustainable consumption (e.g. Halkier 2010).

Advocacy of practice theories emanated in part from dissatisfaction with aspects of the analysis of consumption when viewed through the lens of cultural theory. The context was one of reaction to 'the cultural turn' in the human and social sciences, which was hegemonic during the final quarter of the twentieth century. The cultural turn emphasized the symbolic and the conspicuous aspects of consumption, their role in communication and their support for 'expressive individualism'. Indeed when the editors of the first social science collection addressing sustainable consumption (Cohen and Murphy 2001, p. xi) brought together environmental social scientists with scholars of consumption, the subject area of the latter was described as 'attention on the role of consumption in identity formation and communication'. An even more prevalent, and complementary, tendency was to offer individualistic explanations in terms of the figure of 'the consumer'. Thus analysis of consumption was founded upon models of an empowered individual, exercising freedom of choice through voluntary decisions.

In studying consumption, theories of practice promise new perspectives: first, by providing an alternative to models of individual choice, whether based upon the sovereign or the expressive individual; and second, by uncovering and exploring phenomena normally concealed in cultural analysis. It was a reaction both to the overbearing tendency to offer explanations of action in terms of the individual actor and to the exaggeration of the importance of the symbolic in the steering of consumption. Against the model of the sovereign consumer, practice theory emphasizes routine over actions, flow and sequence over discrete acts, dispositions over decisions, and practical consciousness over deliberation. In reaction to the cultural turn, emphasis is placed upon doing over thinking, the material over the symbolic, and embodied practical competence over expressive virtuosity in the fashioned presentation of self.

When Ortner (1984) spotted a tendency for practice theory to be (re-)emergent in the social sciences during the 1970s, she discussed at length three figures who turned out to dominate subsequent debates in sociological theory in Europe: Bourdieu, Giddens and Foucault. Subsequent work by Schatzki $(1996,2002)$ also played a very important role in reorienting discussion. We suggest that much of the variation in, and potential use of, theories of practice can be attributed to the different positions of these four authors. Of the 
first three, Giddens had the major impact in the early development of sociological approaches to sustainable consumption. Initially Giddens's theory of structuration seemed to offer an attractive general solution to the structure-agency problem. His insistence upon the need to develop an appropriate concept of agency (Giddens 1984), which was in reaction to the earlier dominance of structuralist and functionalist theories, seemed especially attractive and was enthusiastically adopted by leading scholars as a foundation for practice-theoretical approaches to environmentally relevant consumption - by Spaargaren and Shove especially. Despite his seminal influence on the sociology of consumption Bourdieu's work has made little impact in the field of sustainable consumption, though there are currently signs of recuperation. Foucault has been a persistent background influence, as well as providing resources for a small body of work addressing sustainable consumption as 'green governmentality' implicated in the neoliberal project of 'responsibilization of the consumer' (e.g. Rumpala 2011; see Barnett et al. 2011 for a critique of this position).

\subsection{THE SOCIOLOGY OF SUSTAINABLE CONSUMPTION}

Theories of practice have been deployed in a growing corpus of empirical studies of consumption in research areas including eating, recreational enthusiasms and listening to music. However, probably the most important domain of application has been sustainable consumption.

Sustainable consumption was initially conceived as the necessary 'downstream' complement to the 'ecological modernization' of production required in order to achieve a transition towards environmental sustainability (Spaargaren and Martens 2005). Sustainable consumption policy focused attention on the huge impact of specifically domestic consumption and deployed behaviour change strategies drawing primarily on psychology and behavioural economics, which deploy individualistic models. Whilst some influential works of environmental sociology had stressed the role of consumption in the ecological crisis (e.g. Redclift 1996) they failed to provide an adequate account of the determinants of behaviour relevant to environmental impacts. Equally Shove and Warde (2002) noted that the extant sociology of consumption offered limited tools in this area, and that understanding sustainable consumption would require the sociology of consumption to move beyond a focus on the individual consumer to the social organization of consumption. The burgeoning policy area of sustainable consumption offered the sociology of consumption a new research agenda, and theories of practice the theoretical and methodological resources to implement it.

Theories of practice have an affinity with the analysis of sustainable consumption for several reasons. Firstly, one is that the inconspicuous consumption of energy and resources in the use of goods and services in the accomplishment of everyday routine tasks (for example, doing the laundry, showering or commuting) as opposed to simply their acquisition, has profound environmental impacts. Furthermore such use is not amenable to explanations based on models of consumer choice, and approaches to consumption based in cultural theory have little purchase, due to their concern with symbolic display, communication and the presentation of self (Shove and Warde 2002). Secondly, goods and services are primarily put to use for the accomplishment of social practices (for example, sharing a meal, playing sport or gardening), rather than for their consumption per se, drawing attention to the dynamics of social practices for explanatory resources for the escalating environmental impact of consumption (Warde 2005). Thirdly, theories of practice offer the sociology of sustainable consumption an understanding of social action that promised a way out of the cul-de-sac of the 'value-action' or 'attitude-behaviour' gap: the phenomenon of the discrepancy between reported pro-environmental values and obdurately unsustainable behaviour. 
The purported gap between attitudes and actions, which has become the centrepiece of so much policy intervention and analysis, arises from widely shared conceptual premises that social action is driven by anterior conditions, variously: norms (in classical sociology), attitudes (in social psychology) and preferences or interests (in economics). It derives from a common model of the human subject, which Hindess (1990) calls 'the portfolio model', wherein the subject possesses a more or less stable portfolio of beliefs and desires and selects from them to decide on the course of action. This ontology is shared, despite all their apparent opposition, by both theoretical traditions of structuralism and methodological individualism. Thus for the structuralist the 'content of the portfolio is a function of the actor's social location' (Hindess 1990, p. 88). The rational-choice model of the sovereign consumer makes a further refinement of the model, adding the assumption that the actor's portfolio of desires has a utilitarian structure (ibid.).

From the perspective of theories of practice this model of action structurally overestimates the role of deliberation in routine purposive tasks, and fundamentally underestimates the extent to which individuals' autonomous action is constrained by infrastructures and socio-technical systems and by the collective and normative derivation of most consumption, routinely conducted within the context of resource constraints: social, cultural and economic (Southerton et al. 2004).

This said, the topic of agency remains one of considerable controversy. Indeed we suggest that the understanding of agency marks a key contrast between two, relatively distinct, major programmes in the field of sustainable consumption.

\subsection{TWO PRACTICE-THEORETICAL PROGRAMMES FOR SUSTAINABLE CONSUMPTION}

The two programmes can each be exemplified by a key theorist in the sociology of sustainable consumption: Gert Spaargaren and Elisabeth Shove. While there are multiple points of contact between the two, each draws on different intellectual resources, addresses distinct empirical areas of enquiry, and envisages differing political and policy implications.

Spaargaren drew on Giddens's structuration theory to explore the behaviour, roles and capacities of 'citizen-consumers' in promoting the 'ecological modernisation' of consumption, in the context of globalized environmental governance (Spaargaren and Van Vliet 2000). This first programme therefore focuses on purposive projects and social and cultural activities explicitly oriented by sustainable consumption: sustainability policy initiatives and behaviour change programmes; 'citizen-consumer' engagements and 'sustainable lifestyles' (e.g. Spaargaren 2003; Spaargaren and Martens 2005; Spaargaren and Oosterveer 2010).

Shove, on the other hand, is centrally concerned with understanding the dynamics of everyday practices, how practices emerge, persist and disappear, and how expectations and conventions become naturalized. This programme seeks to understand the complex causalities that lead to more (or less) resource-intensive practices (e.g. Shove 2003, 2004), and the implications of such for policy (e.g. Shove 2010; Shove and Walker 2010; Shove et al. 2012; Spurling et al. 2013). Shove suggested a fundamental rethinking of the research agenda for the sociology of sustainable consumption, arguing that:

"[I]nvestigations into the beliefs and actions of self-confessed environmentalists represent something of a distraction. What counts is the big, and in some cases, global swing of ordinary, routinized and taken-for-granted practice ... Only by setting 'the environment' aside as the main focus of attention will it be possible to follow and analyse processes underpinning the normalization of consumption and the escalation of demand." (Shove 2003, p. 9) 
Spaargaren's understanding of the 'transformative capacity' of individual and collective agency mediated by social structures, whilst acknowledging the constraining force of those structures, posited human agency 'as something that could explain the dynamics of systems of provision' (Spaargaren and Van Vliet 2000, p. 63). Shove (2003, pp. 12-13), on the other hand, drawing intellectual inspiration from science and technology studies (e.g. Akrich 1992) and innovation studies (e.g. Rip and Kemp 1998), emphasized how ways of life 'are situated and inscribed in tools, devices and material objects', the 'mutual constitution of technologies and their ... users', and the 'potentially constitutive role of things and sociotechnical systems'. Spaargaren professed optimism in citizen-consumers' conscious efforts to alter the organization of practices, in reflexive subjects' capacity to establish new, more sustainable routines, and in the dynamics of capitalism to shift in a sustainable direction. Shove, by contrast, professed scepticism that environmentally inspired consumers' commitments could redefine conventions of everyday life, questioned whether explicit contestation was a prerequisite for enduring change, and emphasized processes of path-dependency (Shove 2003, 2004; Chappells et al. 2011). Before turning to what appears to be a convergence of the two programmes let us outline the different methodological resources that, at their most distinctive, each offers.

\subsubsection{Citizen-Consumers at the Consumption Junction}

Within Giddens's structuration theory individual behaviour subsists within social practices, the rules and resources of which both enable and constrain actors, and constitute the structures that are involved in the reproduction of social practices. In this recursive relationship structures are both the media and the outcomes of human action (Spaargaren and Van Vliet 2000). This 'duality of structure' is examined methodologically by, on the one hand, 'institutional analysis' of social practices, where agency is bracketed out, and on the other 'the analysis of strategic conduct' in which the rules and resources of practices are taken as given in order to focus on actors' use of structures.

For the purposes of Spaargaren's programme, the relative power of citizen consumers to achieve a reduction in the environmental impacts of different domains of consumption (housing, food, travel and so on) can be assessed through analysis of the rules and resources of the consumption practices afforded them by the different domains' systems of provision (or systemic interactions between consumption and production). The task of policy becomes to enable that power, conceived not simply as capacity for consumer choice of 'green options' but as the enhancing of 'the authority of consumers ... to exert democratic control over the actors involved' (Spaargaren 2003, p. 691). Spaargaren and Oosterveer (2010, p. 1893) offer a conceptualization of environmental power as the capacity of social actors to reduce the environmental impacts of consumption and production where these impacts are directly connected to sets of practices predominantly under the control of other actors'.

Spaargaren's programme thus explicitly seeks to further the 'new consumeroriented environmental politics' that arises in the context of the increasing importance of the hybrid role of citizen-consumer for companies, policy makers and social movements under conditions of globalization and reflexive modernity (Spaargaren 2003, 2006). Core areas that it seeks to address include: the changing role of citizen-consumers in globalizing environmental politics; the changing social relations between producers and citizenconsumers in globalizing systems of provision; the appropriation of socio-technical innovations within social practices; social change as socio-technical innovation rooted in systems of provision, lifestyles or both; the assessment of levels of ecological modernization and the relative capacities of different actor groups to enable transitions towards sustainability in different consumption domains; and the role of companies in incorporating 
sustainability-enabling ideas, information and products into consumption routines of citizenconsumers.

Two central concepts deserve attention: 'lifestyle' and 'consumption junction'. The place of the citizen-consumer within this programme foregrounds Giddens's descriptive concept of lifestyle: a specific form of integration of practices enacted by actors, in which consumption often plays a key role, to form a reasonably coherent unity. Lifestyles are equally the discursive accounts by which actors connect practices, 'clusters of habits and story lines' and 'narratives of self identity' (Spaargaren 2006, p. 24). If Spaargaren's programme foregrounds the cultural politics of sustainable consumption, lifestyle is an organizing principle of that politics, and 'consumption junctions' the sites in which this politics is often fought. Consumption junctions are where demand and provision, or the social practices of consumption and production, meet and where actors may enact social change through incorporating socio-technical innovations into everyday life (Spaargaren 2006; Spaargaren and Van Vliet 2000).

Spaargaren and Oosterveer's (2010) exploration of citizen-consumers' role in effecting change and Spaargaren and van Koppen's (2009) instrumental suggestions for the role of companies in enabling more sustainable consumption routines delineate the programme's empirical approach to practice theory.

\subsubsection{Conventions, Competence and Kit}

Shove aimed to reframe the problem of sustainable consumption from one of the promotion of more efficient, sustainable technologies, to one of the promotion of more sustainable practices; which practices co-evolve with technological innovation and infrastructures of provision. Such an approach animates diverse questions relevant to sustainable consumption, such as: why has daily showering widely replaced weekly bathing? (Hand et al. 2005); what are the dynamics of escalating energy demand from digital technologies? (Røpke and Christiansen 2013); and what accounts for the rapid global diffusion of air conditioning? (Shove et al. 2013). The material and functional properties of things, neglected in cultural analysis, are made central to accounts of consumption.

This reframing recognizes that promoting more efficient technologies alone may not ameliorate their environmental impact: improved refrigeration technology, for example, may simply lead to the use of increased refrigerated space at the same cost. Moreover increased efficiency may have the unintended consequence of inadvertently naturalizing ultimately less sustainable conventions and expectations, that become embedded in routine practices of everyday life and escalate aggregate consumption's environmental impact: 'what matters is the relation between (more or less efficient) technologies, systems and appliances, and co-evolution of routines, habits and practices' (Shove 2004, p. 1054).

In Comfort, Cleanliness and Convenience (2003, p. 61) Shove unpacks dimensions of social and technical co-evolution, and the ensuing dynamics of escalating demand, through these social conventions or 'composite services'. Comfort - in the form of lighting and indoor temperature control - is examined to demonstrate global processes of standardization and convergence, and their local translation. This 'vertical' structuring of normal practice is contrasted with the very different mechanisms of 'horizontal' ordering presented by evolving conventions and practices of cleanliness. Here the circulation of elements of practice - images, meanings, technologies - is again implicated in escalating demand (in, for example, the rapid diffusion of the practice of frequent showering); and an account that cannot be accommodated in standard models of socio-technical co-evolution. 'Convenience' introduces the temporal dimension, which forms an intersection between the two axes, and is itself an engine of change (2003, p. 192). Shove does not present an allencompassing account of the social organization of normality, or a universal schema for social change, but rather identifies multiple intersecting dynamics. The approach does however identify some abstract mechanisms of change, such as a ratcheting of demand 
through unidirectional path-dependency and temporary configurations able to stabilize in more or less resource intensive forms.

This interdependence of technical systems and practices suggests two key insights. First, levels of demand and patterns of consumption are the outcome of both (Shove 2004, p. 1055). Second, there are multiple possible points of intervention and innovation for steering practices towards more sustainable forms. If much of the environmental impact of consumption arises through the routine reproduction of normal life, interventions may be targeted at disrupting or challenging cultural conventions and meanings (Shove 2003).

However Shove's programme also challenges a dominant assumption within sustainable consumption research (e.g. Spaargaren and Van Vliet 2000), that changing embedded habits and practices requires de- and re-routinization through deliberative engagement and reflexive renegotiation: 'An alternative practice-based perspective suggests that enduring change emerges through the amplification of existing social orientations and does not necessarily depend upon explicit contestation and debate' (Chappells et al. 2011, p. 701).

This approach, then, focuses on the dynamics of practice and their relation to escalating impacts of consumption, analysing the intersection of conventions, understandings and competences on the one hand, and institutions, infrastructures and technologies on the other.

\subsection{AGENCY, CHANGE AND CONVERGENCE}

Central to the further development of theories of practice for sustainable consumption has been the work of Schatzki (especially 1996, 2002). Schatzki has rigorously elaborated a social ontology of practice, in critical dialogue with the practice theories of Bourdieu, Foucault and Giddens, by way of the philosophies of Wittgenstein and Heidegger. This ontology establishes a 'strong' version of practice theory in which both social order and individuality result from practices. It asserts that there is no macro level beyond the realm of social practices, which are "not merely "sites" of interaction but are, instead, ordering and orchestrating entities in their own right' (Shove and Walker 2010, p. 471).

The programme we have associated with Shove has attempted to develop the implications of this stance (e.g. Shove and Spurling 2013). This strong practice theory approach advances an abstract description of dynamics between and within practices (e.g. Shove et al. 2012), but without seeking to produce a unified model of change that can be applied across whole categories of practices. Rather it enables the identification of critical, context-specific (often recursive) processes and complex causal interactions that result in resource-intensive patterns of everyday consumption. Key dimensions of such processes are materiality and temporality. Novel material components of practice may either transform or fail to transform existing practices, with important implications for sustainable consumption. Røpke and Christensen (2013) analyse this first process in the context of how the generic functionalities of information and communication technologies (ICTs) become embedded in a huge range of existing everyday practices and projects, transforming many in the process; including those with no self-evident relation to ICTs, such as sports, hobbies and do-ityourself (DIY). Such embedding of digital technologies in everyday life has profound consequences for energy demand and resource use. The second process is explored by YliKauhaluoma et al. (2013) with respect to the obdurate materiality of paper, which resists the promise of the 'paperless office' offered by those self-same digital technologies.

Crucially, these dynamics operate both across space and in time. The temporal ordering of practices, 'embedded conventions of duration, sequence and timing' (Shove 2009, p. 25), and the synchronization of personal and collective schedules, have significant implications for the consumption of energy and the development of infrastructure: in, for example, transport infrastructure designed to cope with rush hours, or energy systems 
designed to cope with peak loads. The temporal coordination of practices, their sequencing and synchronization within collective life, not only has profound importance for the environmental impact of everyday life but equally presents novel opportunities for achieving substantial shifts in behaviours (Southerton et al. 2011; Spurling et al. 2013).

Any brief summary of the field would be incomplete without acknowledging the important recent book by Shove, Pantzar and Watson, The Dynamics of Social Practice (Shove et al. 2012), which is both an important general contribution to the application of practice theory and explicitly orientated to promoting transitions in practice. It presents an avowedly 'radically simplified' account of practice theory, the better to elucidate complex dynamics. Central to this project is to model practices as composed as three generic elements: meaning, competence and material. It stresses the relative independence of the trajectories of these elements of practices from practices themselves. Practices come into being and are transformed through the circulation and recombination of elements. Shove et al. (2012) elaborate Giddens's (1984) notion of the 'reproduction circuit' or feedback between the self-monitoring of actors and social structure. 'Circuits of reproduction' include: the reproduction of practice through the integration of elements; cross-practice configurations of elements that affect the former; and inter-practice circuits (Shove et al. 2012, p. 114).

In the UK, the Sustainable Practices Research Group, SPRG (2010-2013), has explicitly conducted empirical research engaging with the stronger programme and its concerns with the emergence, diffusion, normalization, persistence, change, variation across social space and disappearance of practices. The SPRG applied variations of practice theory to several empirical areas, including: the diffusion of air conditioning (Shove et al. 2013); how eating habits change (Darmon 2013); understanding domestic water consumption through variations in domestic practices (Browne et al. 2013); and comparative international configurations of drinking water (Harvey 2012).

More recently Spaargaren and collaborators have also drawn upon these intellectual resources to address the criticisms that their emphasis on citizen-consumers and lifestyles amounts to a regression to methodological individualism and an exaggeration of individuals' transformative capacities, with a concomitant neglect of materiality and structural constraints (Spaargaren and Oosterveer 2010, p. 1897-1898). As such there has been, to a certain extent, a theoretical convergence of this programme with that of Shove.

However there remain differences in position regarding in particular the nature of change. Indeed some of the aficionados of the stronger programme also have reservations about the manner in which change is analysed. One nuanced but important difference from Spaargaren can be found in a useful distinction. Spaargaren $(2013$, p. 233 ) notes that ' $[i] \mathrm{t}$ is practices that "produce" and co-constitute individuals ... not the other way round"; nevertheless 'human subjectivity is at the heart of process of structuration'. The 'strong' practice theory understanding of practices as entities with causal powers is overshadowed by the model of agency implicit in the optimistic understanding of citizen- consumers as 'change agents'. Social practices become a device for analysing citizen-consumers' roles as bearers of ecological citizenship, political consumption and lifestyle politics (Spaargaren and Oosterveer 2010), rather than practices themselves taking centre stage in the analysis of social change. Political actors overshadow other dynamics, such as the circulation of practice elements, whether concepts or technologies (Shove and Walker 2010), and of endogamous change (Chappells et al. 2011). Conversely the strategic move of Shove away from the 'distraction' of environmentalists' motivations has led to a neglect of the cultural dimensions of sustainable consumption (Spaargaren 2013). Perhaps this programme focuses overzealously on analysing the dynamics of everyday practice as a route to better understanding transitions toward sustainable practices at the expense of collective mobilization and macro-level institutional processes. Thus there appears to be a need to 
construct a plausible set of connections between the habits and routines of everyday life and lay normativity and collective mobilization.

Recently, a number of researchers drawing upon Schatzki and the resources of the 'stronger' version of practice theory have addressed activities organized and represented explicitly in the name of sustainable consumption, which have come to increasing prominence since the early 2000s. Thus, for example: Barnett et al. (2011) have explored practices of 'ethical consumption'; Gram-Hanssen (2011) has analysed an intervention aimed at reducing consumers' standby consumption; Hargreaves (2011) has applied practice theory to an organizational environmental behaviour change programme; Crivits and Paredis (2013) have analysed sustainable food practices; Middlemiss (2011) has addressed initiatives of community-based organizations for sustainable lifestyles; and Wheeler (2012) has examined practices of 'Fairtrade support'. In these cases, participants consider themselves to be acting to make consumption more sustainable.

Similarly Halkier (2010) foregrounds the reflexive effects of the mediatized discourse of sustainable consumption. This is a refreshing contrast to the focus on the routinized, habitual character of 'inconspicuous consumption' that drew attention away from the role of cultural intermediaries, the public sphere and media in the wider dynamics of sustainable consumption. Halkier (2010) put to work the practice component categories of understandings, procedures and engagements (Warde 2005) to explore the performance of everyday food practices in the context of their problematization through media discourses of environmental sustainability, risk and health. Halkier notes that the very problematization of consumption (in which sustainable consumption plays such a significant part) draws attention to consumption routines qua consumption. Indeed the intention of media discourses and the many purposive interventions of non-governmental organizations, public bodies and companies that ascribe societal responsibility to 'consumers' is often to nominate everyday activities explicitly as consumption practices in order to open them up for revision (Halkier 2010; cf. Barnett et al. 2011). This presents a caveat to Warde's (2005, p. 137) contention that consumption is a 'moment in almost every practice' rather than itself being a practice. Halkier argues that an engaged form of environmentally friendly food consumption can indeed be viewed as a practice in its own right, through the integration of a specific set of understandings, routinized procedures and engagement with a normative project of sustainability:

"In identifying with environmentally friendly food consumption, practitioners express understandings in their sayings oriented towards specific tasks (such as using organic food), and practitioners express engagements in their doings that amount to practice projects ... This can be seen as performing political consumption practices." (Halkier 2010, p. 74)

In stressing the everyday normative negotiations attendant upon sustainable food consumption, Halkier points to areas which recent practice theoretical approaches have avoided: discursivity, lay normativity, social interaction ${ }^{2}$ and the creation of norms which produce shared understandings and common procedures. Her empirical research indicates that interaction within social networks and practical procedures is often more important than individual normative commitments in driving the 'normativized performing' characterizing sustainable food consumption (ibid.). This has significant implications for policy interventions, communication strategies and behaviour change initiatives.

Sustainable consumption is a notion born of policy initiatives and much of the practice-theoretical research is ultimately oriented to informing policy. The two programmes offer contrasting approaches to policy, which undoubtedly partly reflects the very different national political contexts of the key protagonists in the Netherlands and the UK. 
Spaargaren's programme seeks to operationalize social science for direct application in policy initiatives - assessing levels of green provisioning, developing 'environmental heuristics' and so forth (e.g. Spaargaren 2003, 2006) - thus working with the grain of conventional politics. Shove (2010), on the other hand, rejects the individualized, voluntaristic model of consumption which dominates policy approaches, those which she calls the attitude-behaviour-choice $(A B C)$ model, which in turn reflect the 'portfolio model' of the actor. Her critique challenges the policy focus on information provision and social marketing in behaviour change programmes, reflecting theoretical scepticism towards the role of deliberative action in changing social practice as well as emphasizing processes of coevolution (Evans et al. 2012; Spurling et al. 2013). Furthermore such framings of policy lead to the 'more powerful drivers of consumption practices and social dynamics that continue to perpetuate undesirable patterns of resource [being] largely ignored' (Chappells et al. 2011, p. 712).

\subsection{PROSPECTS}

Theories of practice have made an important contribution to the study of sustainable consumption. Overcoming traditional theoretical antinomies through positing the generative interdependence of structure and agency enables pertinent accounts of complex causality. Their sensitivity to the constitutive role of material elements (tools, infrastructures) in sociotechnical change and the active appropriation of technologies and commodities in local contexts is specifically suited to the analytical needs of sustainable consumption: identifying systematic links of social, cultural, economic and technological processes of innovation, normalization and disruption. The integration of socio-cultural and material elements is of particular relevance to the multidisciplinary research programmes that have been commonplace in sustainable consumption research and to strategies for political intervention.

There are at least three important outstanding analytic problems whose clarification and resolution would enhance the power of practice theories. The first concerns the relationship between production and consumption. While Shove (2003) set out to develop a framework encompassing innovation in consumption and production and the dynamic process between the two, most practice-theoretical empirical research has engaged in micro-sociological studies of everyday life to the neglect of the sphere of economic production. Shove's programme was at least in part directed against producer-oriented accounts of socio-technical change in innovation studies and the multi-level perspective (MLP) of the 'socio-technical transitions' literature (Geels 2002) (e.g. Shove 2003; Shove and Walker 2010; Shove et al. 2013). However, the 'horizontal' dynamics of end-use consumption and everyday life might now be enhanced by taking greater account of other phases of systems of provision.

MLP, for example, offers a heuristic framework which distinguishes between levels of niche (or relatively unstabilized practice), regime (or relatively stabilized incumbent configurations) and landscape (or broad cultural and historical context). The ontological compatibility of practice theory and MLP is contentious (see Geels 2010; and Schatzki 2011 for a critique). The recent stress of MLP proponents that their model primarily distinguishes degrees of institutionalization, defined as the stability and consistency of interactions and power relations over time and space, goes some way to address these concerns (Geels 2011; Grin 2012; Spaargaren et al. 2012).

Recent pragmatic moves towards a synthesis of practice theory and the sociotechnical transition approaches is therefore a welcome development (Cohen et al. 2013; Crivits and Paredis 2013; Geels 2010, 2011; McMeekin and Southerton 2012Spaargaren et al. 2012; Watson 2012). McMeekin and Southerton (2012) propose, echoing Spaargaren's earlier emphasis on 'consumption junctions', that better conceptualization of the dynamics 
between production and consumption in sustainability transitions would result from a fuller account of the institutional space, the 'mediation junction', in which these processes take place and address the ability of intermediaries 'in terms of their ability to shape elements within the nexus of practices that occupy [that] space' (2012, p. 356).

A second issue concerns the relationship between collective agency and everyday routines which perpetuate and reproduce patterns of consumption. Theories of practice have tended to neglect the role of collective social and political projects, ideologies and cultural discourses. This is ironic given that sustainable consumption was initiated as a purposive project, promoted by powerful collective actors and expressed via a cultural, reflexive discourse. Grin (2012) for example, through a study of the modernization of food consumption and production in the Netherlands, takes practice approaches to task for not acknowledging the extent to which 'regime actors' directly govern and shape practices. Similarly Harvey (2004), in critique of Shove (2003), points to social struggles over standardization as quality-of-life issues; he cites the examples of clean air regulation and improved cleanliness in the workplace.

Barnett et al. (2011) make an important contribution by counteracting a lack of theorization of collective social action and actors. ${ }^{3}$ Challenging the assumption that 'the consumer' is the primary agent of change in efforts to politicize consumption practices, Barnett et al. (2011) draw on practice-theoretical resources to stress how the politicization and problematization of consumption 'is an outcome of organized efforts by a variety of collective actors to practically re-articulate the ordinary ethical dispositions of everyday consumption': "'the consumer" is not so much a locus of sovereignty and agency as it is a rhetorical figure and point of identification only contingently related to the politics of consumption' (Barnett et al. 2011, p. 19). Sustainable consumption is from this perspective understood 'as an organised field of strategic interventions' (ibid., p. 13) in which, following a Foucauldian route, consumption is taken up as the object of problematizing discourse.

A final concern is the relationship between the minutiae of everyday performances of practices and the macro-institutional context. This is a perpetual theoretical dilemma for sociology as a whole, but appears in stark relief with respect to the stronger programme's account of practice bundles.

Arguably, the 'horizontal' circulation of ideas and representations may provide an account of change within discrete practices but says less about the supra-practice configurations that these elements may subtend. How the analytical categories of generic components of practice are conceptualized may have a bearing. Schatzki's (2002) later schema explicitly adds the category 'general understandings'. General understandings are common to many practices and condition the manner in which practices are carried out, as well as being expressed in their performance. They constitute external understandings of the overall project in which the practice is engaged (Nicolini 2012, p. 167). Schatzki gives the example of the Shaker view of labour as a sanctification of the earthly sphere, which conditioned the manner in which many of their labouring practices were carried out, as well as being explicitly formulated in doings and sayings (Schatzki 2002, p. 86).

Schemas (e.g., Shove et al. 2012) which lack analytical differentiation between very general cultural understandings and practice-specific orders of meaning run the risk of obscuring the structuring effects upon practices of widespread, adjacent or overarching cultural discourses. Such discourses may animate purposive programmes, such as those of 'modernization', 'neoliberalism' or indeed 'sustainable consumption', or be found in diffuse but powerful cultural trends such as 'Americanization', or even very general cultural notions such as 'authenticity'. Conceptualizing such general understandings simply as common ideational elements shared by discrete practices potentially misses important processes of change. Shove et al. (2012, p. 110) have recourse to 'meso-level discourses and categories that have orchestrating and co-ordinating effects in their own right', such as obesity, 
'simultaneously reproduced in "micro" and "macro" form', from bathroom scales to public health initiatives. However it is moot whether such a move is compatible with the "high order ontological sameness' of Schatzki's (2011) flat ontology, which itself offers disappointing analytical or explanatory resources. The ends to which practices are put, the kind of objects that they seek to act upon, the nature of problems they admit to, and the form of interventions thus enjoined, suggest patterning and configuration on a suprapractice level. Practice theories at present lack persuasive theoretical or conceptual answers. It is in this context that the conceptual instruments of Bourdieu and Foucault, both of whom managed to reconcile practice-theoretical foundations with macro-level structural and historical explanation, might yet be useful. In their absence there still seems no reason why empirical investigation, and indeed strategic intervention, cannot proceed in a profitable manner.

\section{REFERENCES}

Akrich, M. (1992), 'The de-scription of technical objects', in W. Bijker and J. Law (eds), Shaping Technology/Building Society, Cambridge, MA: MIT Press, pp. 205-244.

Barnett, C., N. Clarke, P. Cloke and A. Malpass (2011), Globalizing Responsibility: The Political Rationalities of Ethical Consumption, Chichester: Wiley-Blackwell.

Bourdieu, P. (1977), Outline of a Theory of Practice. Cambridge: Cambridge University Press.

Browne, A.L., M. Pullinger, W. Medd and B. Anderson (2013), 'Patterns of practice', International Journal of Social Research Methodology, 17 (1), 27-43.

Chappells, H., W. Medd and E. Shove (2011) 'Disruption and change: drought and the inconspicuous dynamics of garden lives', Social and Cultural Geography, 12 (7), 701715.

Cohen, M.J., H.S. Brown and P.J. Vergragt (eds) (2013), Innovations in Sustainable Consumption: New Economics, Socio-technical Transitions and Social Practices, Cheltenham, UK and Northampton, MA, USA: Edward Elgar.

Cohen, M.J. and J. Murphy (eds) (2001), Exploring Sustainable Consumption: Environmental Policy and the Social Sciences, London: Pergamon.

Crivits, M. and E. Paredis (2013), 'Designing an explanatory practice framework', Journal of Consumer Culture, 13 (3), 306-336.

Darmon, I. (2013), 'Change in eating habits: the contribution of new local food infrastructures', SPRG Discussion Paper 3. www.sprg.ac.uk.

Evans, D., A. McMeekin and D. Southerton (2012), 'Sustainable consumption, behaviour change policies and theories of practice', in A. Warde and D. Southerton (eds), The Habits of Consumption, COLLeGIUM 12,1-25, Helsinki Collegium for Advanced Studies.

Geels, F.W. (2002), 'Technological transitions as evolutionary reconfiguration processes: a multi-level perspective and a case study', Research Policy, 31, 1257-1274.

Geels, F.W. (2010), 'Ontologies, socio-technical transitions (to sustainability), and the multilevel perspective', Research Policy, 39 (4), 495-510.

Geels F.W. (2011), 'The multi-level perspective on sustainability transitions: responses to eight criticisms', Environmental Innovation and Societal Transitions, 1, 24-40.

Giddens, A. (1984), The Constitution of Society, Cambridge: Polity Press.

Gram-Hanssen, K. (2011), 'Understanding change and continuity in residential energy consumption', Journal of Consumer Culture, 11, 61-78.

Grin, J. (2012), 'Changing governments, kitchens, supermarkets, firms and farms', in G. Spaargaren, P. Oosterveer and A. Loeber (eds), Food Practices in Transition, London: Routledge, pp. 35-58.

Halkier, B. (2010), Consumption Challenged, Farnham: Ashgate. 
Halkier, B., T. Katz-Gerro and L. Martens (2011), 'Applying practice theory to the study of consumption: theoretical and methodological considerations', Journal of Consumer Culture, 11 (1), 3-13.

Hand, M., D. Southerton and E. Shove (2005), 'Explaining showering: a discussion of the material, conventional, and temporal dimensions of practice', Sociological Research Online, 10 (2), http://www.socresonline.org.uk/10/2/hand.html.

Hargreaves, T. (2011), 'Practice-ing behaviour change: applying social practice theory to proenvironmental behaviour change', Journal of Consumer Culture, 11(1), 79-99.

Harvey, M. (2004), 'Book review: Comfort, Cleanliness and Convenience', Journal of Consumer Culture, 4, 419-421.

Harvey, M. (2012), 'Drinking-water and drinking water: trajectories of provision and consumption in the UK, Taiwan and Delhi', CRESI Working Paper 2012-02, University of Essex.

Hindess, B. (1990), 'Analyzing actors' choices', International Political Science Review, 11 (1), 87-97.

Kaidesoja, T. (2013), 'Overcoming the biases of microfoundationalism', Philosophy of the Social Sciences, 43 (3), 301-322.

MacIntyre, A.C. (1981), After Virtue. London: Duckworth.

McMeekin, A. and Southerton, D. (2012) 'Sustainability transitions and final consumption: practices and socio-technical systems' Technology Analysis and Strategic Management, 24 (4), 27-330

Middlemiss, L. (2011), 'The power of community', Society and Natural Resources, 24 (11), 1157-1173.

Nicolini, D. (2012), Practice Theory, Work and Organization, Oxford: Oxford University Press.

Ortner, S. (1984), 'Theory in anthropology since the sixties', Comparative Study of Society and History, 16, 126-66.

Reckwitz, A. (2002), 'Towards a theory of social practices', European Journal of Social Theory, $5(2), 243-263$.

Redclift, M. (1996), Wasted, London: Earthscan.

Rip, A. and R. Kemp (1998), 'Technological change', in S. Rayner and E. Malone (eds), Human Choices and Climate Change, Columbus, $\mathrm{OH}$ : Battelle, pp. 327-400.

Røpke, I. (2009), 'Theories of practice', Ecological Economics, 68 (10), 2490-2497.

Røpke, I. and T.H. Christensen (2013), 'Transitions in the wrong direction?', in E. Shove and N. Spurling (eds), Sustainable Practices: Social Theory and Climate Change, London: Routledge, pp. 49-68.

Rouse, J. (2006), 'Practice theories', in D.M. Gabbay, P. Thagard and J. Woods (eds), Handbook of Philosophy and Social Science, Vol. 15, Cambridge, MA: Elsevier, pp. 500-540.

Rumpala, Y. (2011), "'Sustainable consumption" as a new phase in a governmentalization of consumption', Theory and Society, 40, 669-699.

Schatzki, T. (1996), Social Practices: A Wittgensteinian Approach to Human Activity and the Social, New York: Cambridge University Press.

Schatzki, T. (2001), 'Introduction: practice theory', in T.R. Schatzki, K. Knorr Cetina and E. Savigny (eds), The Practice Turn in Contemporary Theory, London: Routledge, pp. 10-23.

Schatzki, T. (2002), The Site of the Social, University Park, PA: Pennsylvania State University Press.

Schatzki, T. (2011), 'Where the action is (on large social phenomena such as sociotechnical regimes)', SPRG Working Paper 1, www.sprg.ac.uk.

Schatzki, T.R., K. Knorr Cetina and E. Savigny (eds) (2001), The Practice Turn in Contemporary Theory, London: Routledge. 
Shove, E. (2003), Comfort, Cleanliness and Convenience: The Social Organization of Normality, Oxford: Berg.

Shove, E. (2004), 'Efficiency and consumption: technology and practice', Energy and Environment, 15 (6), 1053-1065.

Shove, E. (2009), 'Everyday practice and the production and consumption of time', in E. Shove, F. Trentmann and R. Wilk (eds), Time, Consumption and Everyday Life, New York: Berg, pp. 17-34.

Shove, E. (2010), 'Beyond ABC: climate change policy and theories of social change', Environment and Planning A, 42, 1273-1285.

Shove, E., M. Pantzar and M. Watson (2012), The Dynamics of Social Practice, London: Sage.

Shove, E. and N. Spurling (eds) (2013), Sustainable Practices: social theory and climate change, London: Routledge.

Shove, E. and G. Walker (2010), 'Governing transitions in the sustainability of everyday life', Research Policy, 39, 471-476.

Shove, E., G. Walker and S. Brown (2013), 'Transnational transitions: the diffusion and integration of mechanical cooling', Urban Studies, 50 (14), 1-14.

Shove, E. and A. Warde (2002), 'Inconspicuous consumption', in R.E Dunlap, F.H. Buttel, P. Dickens and A. Gijswijt (eds), Sociological Theory and the Environment, London: Rowman \& Littlefield, pp. 230-241.

Southerton, D., C. Diaz-Mendez and A. Warde (2011), 'Behavioural change and the temporal ordering of eating practices: a UK-Spain comparison', International Journal of Sociology of Agriculture and Food, 19 (1), 19-36.

Southerton, D., A. Warde and M. Hand (2004), 'The limited autonomy of the consumer: implications for sustainable consumption', in D. Southerton, H. Chappells and B. Van Vliet (eds), Sustainable Consumption: The Implications of Changing Infrastructures of Provision, Cheltenham, UK and Northampton, MA, USA: Edward Elgar, pp. 32-48.

Spaargaren, G. (2003), 'Sustainable consumption: a theoretical and environmental policy perspective', Society and Natural Resources: An International Journal, 16 (8), 687701.

Spaargaren, G. (2006), 'The ecological modernization of social practices at the consumption junction', Discussion paper for the ISA-RC-24 conference Sustainable Consumption and Society, Madison, WI, June.

Spaargaren, G. (2013), 'The cultural dimension of sustainable consumption practices', in M.J. Cohen, H.S. Brown and P.J. Vergragt (eds), Innovations in Sustainable Consumption, Cheltenham, UK and Northampton, MA, USA: Edward Elgar, pp. 229-251.

Spaargaren, G. and S. Martens (2005), 'Globalization and the role of citizen-consumers in environmental politics', in F. Wijen, K. Zoeteman and J. Pieters (eds), A Handbook of Globalisation and Environmental Policy, Cheltenham, UK and Northampton, MA, USA: Edward Elgar, pp. 211-245.

Spaargaren, G. and P. Oosterveer (2010), 'Citizen-consumers as agents of change in globalizing modernity: the case of sustainable consumption', Sustainability, 2010 (2), 1887-1908.

Spaargaren, G., P. Oosterveer and A. Loeber (2012), 'Sustainability transitions in food consumption, retail and production', in G. Spaargaren, P. Oosterveer and A. Loeber (eds), Food Practices in Transitions, London: Routledge, pp. 1-33.

Spaargaren, G. and C.S.A. van Koppen (2009), 'Provider strategies and the greening of consumption practices', in H. Lange and L. Meier (eds), The New Middle Classes, Dordrecht and Heidelberg, Germany; London, UK; New York, USA: Springer, pp. 81100.

Spaargaren, G. and B. Van Vliet (2000), 'Lifestyles, consumption and the environment', Environmental Politics, 9 (1), 50-76. 
Spurling, N., A. McMeekin, E. Shove, D. Southerton and D. Welch (2013), 'Interventions in practice', SPRG Report, www.sprg.ac.uk.

Warde, A. (2005), 'Consumption and theories of practice', Journal of Consumer Culture, 5 (2), pp. 131-153.

Watson, M. (2012), 'How theories of practice can inform transition to a decarbonised transport system', Journal of Transport Geography, 24 (September), 488-496.

Wenger, E. (1998), Communities of Practice, Cambridge: Cambridge University Press. Wheeler, K. (2012), The practice of fairtrade support', Sociology, 46 (1), 126-141.

Yli-Kauhaluoma, S., M. Pantzar and S. Toyoki (2013), 'Mundane materials at work', in E. Shove and N. Spurling (eds), Sustainable Practices, London: Routledge, pp. 69-85.

\footnotetext{
${ }^{1}$ Widely cited definitions include Reckwitz (2002, p. 249), Schatzki (1996, p. 89; 2002, p. 77), Shove et al. (2012, p. 23) and Warde (2005, p. 134).

${ }^{2}$ Halkier points out that social interaction tends to be left implicit in practice theory '"dressed" conceptually as recognition or coordination' and demands more explicit conceptual and analytical elaboration, not least specifically in the area of sustainable consumption where communication processes play such a key role (2010, p. 172). ${ }^{3}$ Kaidesoja $(2013$, p. 311) notes that the distributed approach to human cognition that practice theory tends to support supports a notion of collective agents with emergent causal powers.
} 